\title{
Corneal Ectasia Risk And Percentage Tissue Altered In Myopic Patients Presenting For Refractive Surgery
}

This article was published in the following Dove Press journal:

Clinical Ophthalmology

\author{
Hon Shing Ong $\mathbb{D}^{1-3}$ \\ Mohamed Farook (D) \\ Benjamin Boon Chuan Tan (D) \\ Geraint P Williams ${ }^{1,2}$ \\ Marcony R Santhiago ${ }^{4,5}$ \\ Jodhbir S Mehta ${ }^{1-3,6}$ \\ 'Department of Corneal and External \\ Diseases, Singapore National Eye Centre, \\ Singapore, Singapore; ${ }^{2}$ Tissue Engineering \\ and Stem Cell Group, Singapore Eye \\ Research Institute, Singapore, Singapore; \\ ${ }^{3}$ SingHealth Duke-NUS Ophthalmology \\ and Visual Sciences Academic Clinical \\ Programme, Duke-NUS Graduate \\ Medical School, Singapore, Singapore; \\ ${ }^{4}$ Department of Ophthalmology, Federal \\ University of Rio de Janeiro, Rio de \\ Janeiro, Brazil; ${ }^{5}$ Department of \\ Ophthalmology, University of Sao Paulo, \\ Sao Paulo, Brazil; ${ }^{6}$ School of Material \\ Science and Engineering, Nanyang \\ Technological University, Singapore, \\ Singapore
}

Purpose: A percentage tissue altered (PTA) score of $\geq 40 \%$ has been advocated as an independent indicator of post-operative ectasia risk following laser in-situ keratomileusis (LASIK). This study was performed to test the hypothesis that refractive procedures, such as laser-assisted subepithelial keratectomy (LASEK) or small incision lenticule extraction (SMILE), may alter the range of PTA, within which refractive corneal surgery can be safely performed.

Setting: Refractive department, tertiary ophthalmic hospital.

Design: Retrospective observational study.

Methods: Review of case notes was performed for patients who presented for refractive surgeries, other than LASIK. To determine the risk of corneal ectasia for each patient prior to refractive surgery, we estimated what each patient's PTA would have been if they had undergone LASIK. The Randleman Ectasia Risk Score System (ERSS) was also calculated. Results: 114 eyes (66 patients) were included. 94 eyes underwent SMILE. 20 eyes underwent LASEK. A significant proportion of eyes had PTA $\geq 40 \%$ - SMILE eyes: up to $31.9 \%$, LASEK eyes: up to $60.0 \%$ (at presumed LASIK flap of $120 \mu \mathrm{m}$ ). The maximum calculated PTA was up to $47.9 \%$ in the SMILE group and up to $51.5 \%$ in the LASEK group. Using ERSS, $12.8-16 \%$ of SMILE eyes and $15.0-80.0 \%$ of LASEK eyes would have been considered to have moderate-tohigh ectasia risk. No post-surgical ectasia was observed at 3 years.

Conclusion: SMILE and LASEK alter the range of PTA, within which corneal refractive surgery may be performed with a lower risk of developing post-operative corneal ectasia; a safe PTA threshold needs to be determined for these procedures before recommendations for clinical practice can be made.

Keywords: percentage tissue altered, ectasia, refractive surgery, laser in situ keratomileusis, laser-assisted sub-epithelial keratectomy, small incision lenticule extraction

\section{Introduction}

Despite significant technological advancements in refractive surgery, laser in situ keratomileusis (LASIK) remains the predominant procedure performed for the correction of myopia. ${ }^{1}$ It involves the creation of a corneal flap using a mechanical microkeratome or femtosecond laser; this flap is then reflected back, and an excimer laser is used to reshape the underlying corneal stromal bed. LASIK provides rapid post-operative visual improvement with minimal patient discomfort. ${ }^{1}$ It has been shown to produce predictable and stable visual outcomes. ${ }^{1}$

Corneal ectasia is one of the most feared complications following corneal refractive surgery as it can result in an irreversible loss of both uncorrected and best-corrected visual acuity. Photoablation of the cornea results in significant changes in its structure and biomechanical properties. ${ }^{2,3}$ As the anterior corneal stroma is $25 \%$ stronger than the
Correspondence: Hon Shing Ong; Jodhbi S Mehta

Department of Corneal and External Diseases, Singapore National Eye Centre, II Third Hospital Avenue, Singapore I6875I, Singapore

Tel +6562277255

Email honshing@gmail.com;

jodmehta@gmail.com 
posterior stroma, it contributes more to the overall cohesive tensile strength. ${ }^{4-7}$ Depending on the planned flap thickness, disrupting the anterior lamellar fibres of the corneal stroma during flap creation in LASIK can, therefore, weaken the cornea's biomechanical stability. Corneal ectasia occurs when the biomechanical integrity of the cornea is compromised with tissue alteration beyond a safe threshold required to maintain its shape and curvature, and there is consequent, irreversible corneal thinning and steepening. ${ }^{8}$ The risk of corneal ectasia following LASIK is well described. ${ }^{9-11}$ It has been reported to occur in $0.03 \%$ to $0.9 \%$ of eyes undergoing LASIK, ${ }^{9,12-14}$ but this is likely to be an underestimate of its true incidence. It can occur days to years following surgery., $9,15-17$

The percentage tissue altered (PTA) metric, representing the percentage of anterior corneal tissue that is modified during refractive surgery, has been described as an independent indicator of post-operative corneal ectasia risk, for patients undergoing LASIK. ${ }^{18-21}$ The PTA takes into account the integrated relationship between pre-operative corneal thickness, ablation depth, and flap thickness and provides a measure of the amount of biomechanical change that occurs following a LASIK procedure. Among patients with normal pre-operative corneal topographies, a PTA of $\geq 40 \%$ was identified as the single, most significant independent indicator for predicting the development of corneal ectasia (OR 223.3, CI 28.8 to 1729.7). ${ }^{18}$ Among patients with suspicious pre-operative corneal topographies, PTA has still been reported to provide the highest discriminative capability for identifying those at risk of corneal ectasia. In addition, for patients with remarkable signs of pre-operative topographic abnormality, it has been found that a lower threshold value of PTA may predict significant risk. ${ }^{19}$

Alternative laser refractive procedures to LASIK for the surgical correction of myopia include: advanced surface ablation (ASA) procedures such as laser-assisted subepithelial keratectomy (LASEK) and small incision lenticule extraction (SMILE). In the absence of creating stromal flaps, ASA procedures are well established and are considered to offer better biomechanical stability than LASIK. $^{22}$ SMILE is the latest technique introduced for flapless corneal refractive surgery. It involves the creation of a lenticule with a femtosecond laser and the removal of this lenticule through a small incision. ${ }^{23,24}$ Since its introduction in 2011, there has been a steady increase in the number of SMILE surgeries performed for the treatment of myopia, as an alternative to excimer-based laser refractive surgeries. One of the postulated benefits of SMILE is better post-operative corneal biomechanical integrity. This postulation is based on mathematical modelling and finite-element analyses. ${ }^{25,26}$ Clinically, however, this has been more difficult to show. Two studies demonstrated that for eyes with myopia of $>6.0 \mathrm{D}$, there was less disruption of biomechanical stability, measured with an ocular response analyzer (ORA; Reichert Ophthalmic Instruments, Buffalo, NY, USA), after SMILE compared to LASIK. ${ }^{27,28}$ A third study used both the ORA and Corvis ST (Oculus, Wetzlar, Germany), also arrived at the same conclusion. ${ }^{29}$ However, other studies have reported no significant differences between SMILE and LASIK corneal biomechanics, evaluated using either the ORA $^{30}$ or Corvis ST. ${ }^{30-32}$ Thus, the purported benefit of SMILE offering better biomechanical stability than LASIK has not yet been determined formally in clinical practice. Indeed, some cases of corneal ectasia following SMILE have been reported; albeit, many of these cases had preoperative topographical abnormalities. ${ }^{33-38}$

Given that less corneal stromal fibres are disrupted in flapless procedures such as ASA or SMILE (compared to LASIK), we hypothesized that these procedures may alter the range of PTA within which corneal refractive surgery may be performed safely. Like ASA, there is likely to be a "grey area" where a patient may potentially be at higher risk of ectasia with LASIK, but may be able to undergo SMILE safely. To test this hypothesis, we retrospectively reviewed the case notes of patients who presented for corneal refractive surgeries other than LASIK (i.e. SMILE or LASEK). Based on their examination findings at presentation, we determined the Randleman Ectasia Risk Score System (ERSS) grades and calculated the PTA scores they would have had hypothetically if they had undergone LASIK. Post-operatively, each patient was monitored for signs of corneal ectasia.

\section{Methods}

This retrospective study reviewed case notes of patients who presented for refractive surgery other than LASIK, from January 2012 to January 2014 at the Singapore National Eye Centre, an ophthalmic tertiary referral centre. The study protocol was approved by the SingHealth Institutional Review Board (CIRB reference number: 2011/109/A), and the study adhered to the tenets of the Declaration of Helsinki. All participants consented to the review of their medical records. 


\section{Participants}

All patients were adults ( $\geq 21$ years of age) who had a diagnosis of myopia with a manifest refraction of $\leq 10.00$ dioptres (D) spherical equivalent prior to refractive surgery. Patients with keratoconus or suspected keratoconus on clinical examination or corneal tomography, including suspicious or abnormal Belin-Ambrósio enhanced ectasia display (BAD), ${ }^{39}$ were excluded, as were patients with previous ocular surgery, autoimmune conditions, severe dry eyes, active ocular, or systemic disease likely to affect corneal wound healing and patients using any systemic or ocular medication.

\section{Data Collection}

Data collected from case notes included patient demographics, pre- and post-operative manifest refraction, preoperative and post-operative uncorrected distance visual acuity (UDVA), pre-operative and post-operative best-corrected distance visual acuity (CDVA), pre-operative central corneal thickness (CCT), and indices from Scheimpflug colour corneal tomography (Pentacam, Oculus).

\section{Pre-Operative Assessment}

All patients had a standard pre-operative evaluation including slit-lamp and dilated fundus examinations, $\log \mathrm{MAR}$ UDVA assessment, subjective manifest refractions with CDVA assessment, CCT measurement using ultrasound corneal pachymetry, and Scheimpflug colour corneal tomography (Pentacam, Oculus).

\section{Post-Operative Assessment}

All patients had a standard post-operative evaluation including slit-lamp examination, logMAR UDVA, subjective manifest refractions with CDVA, and Scheimpflug colour corneal tomography (Pentacam, Oculus). Postoperative evaluations were performed at the following time points: 1 day, 1 week, and 1, 3, 12, and 36 months. All adverse events were documented.

For the peri-operative assessments, a single optometrist (MF) obtained all visual acuities and refraction measurements. Measurements were conducted in a single room under consistent photopic lighting conditions. Being a single-centred study, similar device platforms to obtain ultrasound pachymetry and corneal tomography were used for all patients.

\section{Risk Of Corneal Ectasia If Lasik Were To Be Performed}

To determine the risk of corneal ectasia for each patient prior to refractive surgery, we estimated what each patient's PTA would have been hypothetically if they had undergone LASIK. To further stratify the ectasia risk, we also calculated the ERSS scores.

PTA described for LASIK is calculated with the formula: $\mathrm{PTA}=(\mathrm{FT}+\mathrm{AD}) / \mathrm{CCT}(\mathrm{FT}=$ flap thickness, $\mathrm{AD}=$ ablation depth, and CCT $=$ pre-operative central corneal thickness). Using this formula, the PTA was estimated for all eyes, using standard LASIK ablation depths and flap thicknesses (100 $\mu \mathrm{m}, 110 \mu \mathrm{m}$, and $120 \mu \mathrm{m})$. The ERSS score was determined using methods described by Randleman et $\mathrm{al}^{10}$. Briefly, a point score was assigned to each of the following variables: (i) pre-operative topographic pattern, (ii) RSB thickness, (iii) patient age, (iv) pre-operative CCT, and (v) pre-operative myopia. The ERSS is the sum of these scores. Risk of corneal ectasia following LASIK was classified as: low (ERSS $=0$ to 2 ), moderate (ERSS $=3$ ), or high (ERSS $\geq 4$ ). RSB thickness was estimated as pre-operative CCT (flap thickness + calculated central ablation depth thickness).

\section{Post-Operative Corneal Ectasia}

Post-operative corneal ectasia was defined as: (i) increasing myopia or astigmatism (change in manifest refraction of 2 dioptres or more in either sphere or cylinder) and (ii) progressive abnormality on corneal topographies not present in pre-operative scans. ${ }^{9,19}$ Topographic abnormalities include: inferior topographic steepening of 3 dioptres or more compared with the immediate postoperative appearance ${ }^{9}$ and asymmetric patterns (e.g. asymmetric bowtie, inferior steep or skewed radial axis, and increase in posterior elevation). ${ }^{11}$

\section{Surgical Procedures SMILE}

All SMILE procedures were performed by a single surgeon (JSM) using a 500-kHz femtosecond laser platform (VisuMax, Carl Zeiss Meditec, Germany). A previously described standard technique with the following parameters was used: $120 \mu \mathrm{m}$ cap thickness, $7.5 \mathrm{~mm}$ cap diameter, 6.0 to $6.5 \mathrm{~mm}$ lenticule optical zone, and $145 \mathrm{~nJ}$ power with side-cut angles at 90 degrees. ${ }^{40,41}$

\section{LASEK}

All LASEK procedures were performed by a single surgeon (JSM) using an excimer laser platform (Wavelight EX500, Alcon, Texas, USA). Corneal epithelium was 
debrided following a 60 s $20 \%$ alcohol application. Mitomycin C $0.02 \%$ was applied for $60 \mathrm{~s}$ to the stromal bed, following excimer laser treatment.

\section{Statistical Analysis}

The programme, Statistical Package for the Social Sciences software (version 17.0, SPSS, Inc.), was used for statistical analysis. Means and standard deviations were calculated for all continuous variables. Frequency distribution and percentages were determined for categorical variables. Comparisons between post-operative and pre-operative values, for manifest refractions and visual acuities, were carried out using the paired sample $t$-test. Differences in the distributions between groups were analysed using the independent $t$-test. Differences in the distributions of categorical variables between groups were analysed using the Chi-squared test. A $p$ value $<0.05$ was considered significant. As variance between eyes from the same subject is usually less than the variance between different subjects, for pre-operative and post-operative data, statistical adjustments were made in accordance to previously published guidelines to correct for potential confounding effects. ${ }^{42}$

\section{Results}

The study population included 114 eyes (66 patients) (Table 1). Of these, 94 eyes (82.5\%) from 56 patients had SMILE procedures. 20 eyes (17.5\%) from 10 patients had LASEK. The mean age of patients was $30.0 \pm 7.0$ years, and 35/66 (53.0\%) were male. The mean pre-operative spherical equivalent refractive error treated was $-5.71 \pm 2.07 \mathrm{D}$.

Table 2 presents the pre-operative assessments and post-operative outcomes of all recruited patients. As this study includes patients with 3-years follow-up, the visual and refractive outcomes of SMILE were from procedures performed before 2013. This reflects data from our previous paper published in $2015 .{ }^{43}$ Since optimizing centration and nomogram adjustment, our current SMILE visual outcomes have improved. ${ }^{44}$ However, as this study evaluates pre-operative corneal ectasia risks from PTA and ERSS, rather than post-operative visual or refractive outcomes, results of risks determined from in this study would not have been different even if data of eyes that had more recently undergone SMILE were used.

\section{Percentage Tissue Altered (PTA) Of All I I 4 Eyes In Study, Had LASIK Been Performed}

For a presumed LASIK flap thickness of $120 \mu \mathrm{m}$, the mean PTA score of all study eyes would have been $37.4 \pm 6.2 \%$.
A total of $42 / 114$ (36.8\%) eyes would have had PTA $\geq 40 \%$ (Figure 1A). For a presumed LASIK flap thickness of 110 $\mu \mathrm{m}$, the mean PTA score would have been $35.5 \pm 6.1 \%$. A total of 29/114 (25.4\%) eyes would have had PTA $\geq 40 \%$. For a presumed LASIK flap thickness of $100 \mu \mathrm{m}$, the mean PTA would have been $33.7 \pm 6.0 \%$, and 18/114 (15.8\%) eyes would have had PTA $\geq 40 \%$.

\section{Results For Patients Who Had Small Incision Lenticule Extraction (SMILE) [n=94]}

The mean pre-operative spherical equivalent refractive error of eyes was $-5.76 \pm 2.17 \mathrm{D}$.

\section{PTA Scores And ERSS Calculations For Eyes Which Had SMILE (Figure IB, Table I)}

Had these eyes undergone LASIK, for a presumed flap thickness of $120 \mu \mathrm{m}$, the mean PTA score, of eyes that had SMILE, would have been $36.3 \pm 5.8 \%$. A total of $30 / 94$ (31.9\%) eyes would have had PTA $\geq 40 \%$ and the maximum PTA score would have been 47.9\%. Also, 31/94 $(33.0 \%)$ eyes would have had ERSS $=0,26 / 94(27.7 \%)$ eyes would have had ERSS = 1, 22/94 (23.4\%) eyes would have had ERSS $=2,11 / 94(11.7 \%)$ eyes would have had ERSS $=3$, and $4 / 94$ (4.3\%) eyes would have ERSS $\geq 4$. Thus, 15/94 (16.0\%) eyes would have been considered to have moderate-to-high risk of ectasia following LASIK.

For a presumed LASIK flap thickness of $110 \mu \mathrm{m}$, the mean PTA score of these eyes would have been $34.5 \pm 5.8 \%$. A total of 18/94 (19.1\%) eyes would have had PTA $\geq 40 \%$ and the maximum PTA score would have been $46.1 \%$. A total of 32/94 (34.0\%) eyes would have had ERSS $=0,30 / 94$ $(31.9 \%)$ eyes would have had ERSS $=1,20 / 94(21.3 \%)$ eyes would have had ERSS $=2,8 / 94$ (8.5\%) eyes would have had ERSS $=3$, and 4/94 (4.3\%) eyes would have had ERSS $\geq 4$. $12 / 94$ (12.8\%) eyes would have been considered to have moderate-to-high risk of ectasia following LASIK.

For a presumed LASIK flap thickness of $100 \mu \mathrm{m}$, the mean PTA score of these eyes would have been $32.7 \pm 5.8 \%$. A total of $10 / 94$ (10.6\%) eyes would have had PTA $\geq 40 \%$ and the maximum calculated PTA score would have been 44.2\%. Also, 33/94 (35.1\%) eyes would have had ERSS $=0$, 29/94 (30.9\%) eyes would have had ERSS $=1,20 / 94$ $(21.3 \%)$ eyes would have had ERSS $=2,9 / 94$ (9.6\%) eyes would have had ERSS $=3$, and 3/94 (3.2\%) eyes would have had ERSS $=4$. Thus, 12/94 (12.8\%) eyes would have been considered to have moderate-to-high risk of developing ectasia following LASIK. 
Table I Pre-Operative Patient Demographics Of All Eyes In Study Who Subsequently Underwent Small Incision Lenticule Extraction (SMILE) Or Laser-assisted sub-epithelial keratectomy (LASEK)

\begin{tabular}{|c|c|c|c|c|}
\hline Variables & Total Eyes & SMILE* & LASEK & p-value" \\
\hline Number (\%) & $\begin{array}{l}\text { II } 4(100 \%) \text { of } 66 \\
\text { patients }\end{array}$ & $\begin{array}{l}94(82.5 \%) \text { of } 56 \\
\text { patients }\end{array}$ & $\begin{array}{l}20(17.5 \%) \text { of } 10 \\
\text { patients }\end{array}$ & \\
\hline $\begin{array}{l}\text { Age (years) (mean }[M] \pm \text { standard deviation }[S D] \text {, range } \\
{[R] \text { ) }}\end{array}$ & $\begin{array}{l}30.0 \pm 7.0 \\
21.0 \text { to } 53.1\end{array}$ & $\begin{array}{l}30.7 \pm 7.3 \\
21.0 \text { to } 53.1\end{array}$ & $\begin{array}{l}27.1 \pm 4.2 \\
22.4 \text { to } 33.4\end{array}$ & $0.278^{\dagger \ddagger}$ \\
\hline Male gender (n, \%) & $35(53.0 \%)$ & $28(50.0 \%)$ & 7 (70.0\%) & $0.226^{\dagger \S}$ \\
\hline Central corneal thickness $(M \pm S D, R)$ & $\begin{array}{l}541.1 \pm 39.1 \\
437 \text { to } 646\end{array}$ & $\begin{array}{l}553.6 \pm 28.9 \\
504 \text { to } 646\end{array}$ & $\begin{array}{l}482.25 \pm 24.4 \\
467 \text { to } 528\end{array}$ & $<0.0001^{\text {t† }}$ \\
\hline Sphere (D) $(M \pm S D, R)$ & $\begin{array}{l}-5.42 \pm 2.06 \\
0.00 \text { to }-9.50\end{array}$ & $\begin{array}{l}-5.47 \pm 2.15 \\
0.00 \text { to }-9.50\end{array}$ & $\begin{array}{l}-5.20 \pm 1.55 \\
-3.00 \text { to }-7.75\end{array}$ & $0.748^{\dagger \ddagger}$ \\
\hline Cylinder (D) $(M \pm S D, R)$ & $\begin{array}{l}1.00 \pm 0.65 \\
0.00 \text { to } 3.50\end{array}$ & $\begin{array}{l}1.00 \pm 0.69 \\
0.00 \text { to } 3.50\end{array}$ & $\begin{array}{l}0.99 \pm 0.46 \\
0.00 \text { to } 2.00\end{array}$ & $0.467^{\dagger \ddagger}$ \\
\hline Spherical equivalent $(D)(M \pm S D, R)$ & $\begin{array}{l}-5.71 \pm 2.07 \\
-1.25 \text { to }-10.00\end{array}$ & $\begin{array}{l}-5.76 \pm 2.17 \\
-0.75 \text { to }-9.75\end{array}$ & $\begin{array}{l}-5.47 \pm 1.52 \\
-3.00 \text { to }-7.63\end{array}$ & $0.883^{\dagger \neq}$ \\
\hline \multicolumn{5}{|l|}{ Percentage tissue altered (PTA) } \\
\hline LASIK-I00 $(M \pm S D, R)$ & $\begin{array}{l}33.7 \pm 6.0 \\
17.2 \text { to } 46.9\end{array}$ & $\begin{array}{l}32.7 \pm 5.8 \\
17.2 \text { to } 44.2\end{array}$ & $\begin{array}{l}38.1 \pm 5.4 \\
30.3 \text { to } 46.9\end{array}$ & $<0.0001^{\ddagger}$ \\
\hline LASIK-IIO (M $\pm S D, R)$ & $\begin{array}{l}35.5 \pm 6.1 \\
18.7 \text { to } 49.2\end{array}$ & $\begin{array}{l}34.5 \pm 5.8 \\
18.7 \text { to } 46 . \mid\end{array}$ & $\begin{array}{l}40.1 \pm 5.5 \\
32.2 \text { to } 49.2\end{array}$ & $<0.0001^{\ddagger}$ \\
\hline LASIK-I $20(M \pm S D, R)$ & $\begin{array}{l}37.4 \pm 6.2 \\
20.3 \text { to } 51.5\end{array}$ & $\begin{array}{l}36.3 \pm 5.8 \\
20.3 \text { to } 47.9\end{array}$ & $\begin{array}{l}42.2 \pm 5.5 \\
34.1 \text { to } 51.5\end{array}$ & $<0.000 \mathrm{I}^{\ddagger}$ \\
\hline
\end{tabular}

Notes: *3। eyes had 3-year followup data. "Comparing SMILE and LASEK eyes. ${ }^{\dagger}$ Comparing SMILE and LASEK eyes with 3 -year follow-up data. ${ }^{\ddagger}$ Paired sample $t$-test. ${ }^{\S}$ Chisquare test.

Abbreviations: D, dioptres; LASIK-100, PTA based on flap thicknesses of $100 \mu \mathrm{m}$; LASIK-II 0, PTA based on flap thicknesses of II $0 \mu$ m; LASIK-I20, PTA based on flap thicknesses of $120 \mu \mathrm{m}$.

\section{Efficacy}

At 3 months following SMILE, the mean post-operative LogMAR UDVA was $0.04 \pm 0.10$. This was $0.0 \pm 0.08$ at 3 years. The efficacy index (ratio of postoperative UDVA to mean preoperative CDVA) was $0.92 \pm 0.20$ and $0.99 \pm 0.21$ at 3 months and 3 years, respectively (Figure 2A, B).

\section{Predictability}

At 3 months, $84.0 \%$ of eyes were within $\pm 1.00 \mathrm{D}$ of target refraction (Figure 2C). The attempted and achieved corrections are shown in Figure 2D.

\section{Stability}

Three-year follow-up data were available for 16 patients (31 eyes). Changes in the spherical equivalent of manifest refraction, as a function of time, are shown in Figure 2E. For all 31 eyes, the post-operative refraction remained stable. Between the 3 months and 3 years follow-up time points, the difference in the mean spherical equivalent of manifest refraction was: $-0.32 \pm 0.39 \mathrm{D} ; 14.5 \%$ of eyes had a change in SE by $>0.50 \mathrm{D}$.

\section{Safety And Adverse Events}

At 3 months follow-up, the mean post-operative $\log$ MAR CDVA was $-0.04 \pm 0.07$. This was $-0.01 \pm 0.06$ at 3 years. The safety index (ratio of mean postoperative CDVA to mean preoperative CDVA) was $1.04 \pm 0.16$ and $1.17 \pm 0.18$, at 3 months and 3 years, respectively (Figure 2F). At 3 months follow-up, 21/94 (22.3\%) eyes gained one line in CDVA and 5/94 (5.3\%) eyes lost one line. At 3 years follow-up, 16/31 $(51.6 \%)$ eyes gained one line in CDVA and $1 / 31(3.2 \%)$ eyes lost one line. None of the 31 eyes, that had 3-year follow-up data, were found to have post-surgical corneal ectasia. Of these eyes, for a presumed LASIK flap thickness of $120 \mu \mathrm{m}$, $110 \mu \mathrm{m}$, and $100 \mu \mathrm{m}$, the proportion of eyes with PTA $\geq 40 \%$ would have been $9 / 31(29.0 \%), 8 / 31$ (25.8\%), and $4 / 31$ (12.9\%) respectively, had LASIK been performed. 
Table 2 Pre-Operative And 3 Months Post-Operative Patient Demographics In Eyes Undergoing SMILE Procedures ( $\mathrm{n}=94)$ And LASEK Procedures $(n=20)$ For Treatment Of Myopia

\begin{tabular}{|c|c|c|c|c|c|c|}
\hline \multirow[b]{2}{*}{ Variables } & \multicolumn{3}{|l|}{ SMILE } & \multicolumn{3}{|l|}{ LASEK } \\
\hline & Pre-Operative & 3 Months Post-Operative & p-value & Pre-Operative & 3 Months Post-Operative & p-value \\
\hline \multicolumn{7}{|l|}{ Sphere (D) } \\
\hline $\begin{array}{l}\text { Mean } \pm S D \\
\text { Range }\end{array}$ & $\begin{array}{l}-5.47 \pm 2.15 \\
0.00 \text { to }-9.50\end{array}$ & $\begin{array}{l}0.243 \pm 0.45 \\
-1.25 \text { to } 1.00\end{array}$ & $<0.000 I^{*}$ & $\begin{array}{l}-5.20 \pm 1.55 \\
-3.0 \text { to }-7.75\end{array}$ & $\begin{array}{l}0.38 \pm 0.30 \\
0.00 \text { to } 1.00\end{array}$ & $<0.000 I^{*}$ \\
\hline \multicolumn{7}{|l|}{ Cylinder (D) } \\
\hline $\begin{array}{l}\text { Mean } \pm \text { SD } \\
\text { Range }\end{array}$ & $\begin{array}{l}1.00 \pm 0.69 \\
0.00 \text { to } 3.50\end{array}$ & $\begin{array}{l}0.30 \pm 0.27 \\
0.00 \text { to } 1.00\end{array}$ & $<0.000 I^{*}$ & $\begin{array}{l}0.99 \pm 0.46 \\
0.00 \text { to }-2.00\end{array}$ & $\begin{array}{l}0.19 \pm 0.23 \\
0.00 \text { to }-0.50\end{array}$ & $0.001 *$ \\
\hline \multicolumn{7}{|c|}{ Spherical equivalent (D) } \\
\hline $\begin{array}{l}\text { Mean } \pm \text { SD } \\
\text { Range }\end{array}$ & $\begin{array}{l}-5.76 \pm 2.17 \\
-0.75 \text { to }-9.75\end{array}$ & $\begin{array}{l}0.08 \pm 0.47 \\
-1.50 \text { to } 0.75\end{array}$ & $<0.000 I^{*}$ & $\begin{array}{l}-5.47 \pm 1.52 \\
-3.00 \text { to }-7.63\end{array}$ & $\begin{array}{l}0.28 \pm 0.34 \\
-0.25 \text { to } 1.00\end{array}$ & $<0.000 I^{*}$ \\
\hline \multicolumn{7}{|c|}{ UDVA (LogMAR) } \\
\hline $\begin{array}{l}\text { Mean } \pm \text { SD } \\
\text { Range }\end{array}$ & $\begin{array}{l}1.57 \pm 0.37 \\
0.40 \text { to } 1.85\end{array}$ & $\begin{array}{l}0.04 \pm 0.10 \\
-0.15 \text { to } 0.40\end{array}$ & $<0.0001 *$ & $\begin{array}{l}1.45 \pm 0.42 \\
0.54 \text { to } 1.85\end{array}$ & $\begin{array}{l}0.02 \pm 0.40 \\
0.00 \text { to } 0.10\end{array}$ & $<0.000 I^{*}$ \\
\hline \multicolumn{7}{|c|}{ CDVA (LogMAR) } \\
\hline $\begin{array}{l}\text { Mean } \pm \text { SD } \\
\text { Range }\end{array}$ & $\begin{array}{l}-0.01 \pm 0.03 \\
-0.15 \text { to } 0.10\end{array}$ & $\begin{array}{l}-0.04 \pm 0.07 \\
-0.15 \text { to } 0.10\end{array}$ & $0.001 *$ & $\begin{array}{l}0.0 \pm 0.00 \\
0.00 \text { to } 0.00\end{array}$ & $\begin{array}{l}-0.25 \pm 0.05 \\
-0.12 \text { to } 0.00\end{array}$ & $0.168^{*}$ \\
\hline
\end{tabular}

Note: *Paired sample t-test (corrected for correlation between eyes from same subjects).

Abbreviations: SD, standard deviation; D, dioptres; UDVA, uncorrected distance visual acuity; CDVA, corrected distance visual acuity.

\section{Results For Patients Who Had Laser- assisted sub-epithelial keratectomy (LASEK) [ $\mathrm{n}=20]$}

20 eyes (10 patients) underwent LASEK for myopia during the same time period. The mean pre-operative spherical equivalent refractive error of eyes was $-5.47 \pm 1.52 \mathrm{D}$. Three-year follow-up data were available for all 20 eyes. Pre-operative assessments and post-operative outcomes are presented in Table 2.

Baseline characteristics such as age, sex, and preoperative refraction were similar to the SMILE eyes that had 3-year follow-up data (Table 1).

\section{PTA Scores And ERSS Calculations For Eyes That} Had LASEK (Figure IB, Table I)

Had these eyes undergone LASIK, for a presumed flap thickness of $120 \mu \mathrm{m}$, the mean PTA score of eyes that had LASEK would have been $42.2 \pm 5.5 \%$. A total of $12 / 20$ $(60.0 \%)$ eyes would have had PTA $\geq 40 \%$ and the maximum calculated PTA score would have been 51.5\%. Also, 1/20 $(5.0 \%)$ eyes would have had ERSS $=0,3 / 20(15.0 \%)$ eyes would have had ERSS $=2,1 / 20(5.0 \%)$ eyes would have had
ERSS $=3$, and 15/20 (75.0\%) eyes would have ERSS $\geq 4$. Thus, $16 / 20(80.0 \%)$ eyes would have been considered to have moderate to high risk of ectasia following LASIK.

For a presumed LASIK flap thickness of $110 \mu \mathrm{m}$, the mean PTA score of these eyes would have been $40.1 \pm 5.5 \%$. A total of $11 / 20(55.5 \%)$ eyes would have had PTA $\geq 40 \%$ and the maximum calculated PTA score would have been 49.2\%. Also, 1/20 (5.0\%) eyes would have had $\mathrm{ERSS}=0,4 /$ $20(20.0 \%)$ eyes would have had ERSS $=2$, and 15/20 $(75.0 \%)$ eyes would have ERSS $\geq 4$. Thus, 15/20 (75.0\%) eyes would have been considered to have moderate-to-high risk of ectasia following LASIK.

For a presumed LASIK flap thickness of $100 \mu \mathrm{m}$, the mean PTA score of these eyes would have been $38.1 \pm$ $5.4 \%$. A total of $8 / 20(40.0 \%)$ eyes would have had PTA $\geq 40 \%$ and the maximum calculated PTA score would have been $46.9 \%$. 8/20 (40.0\%) eyes would have had ERSS $=0$, $5 / 20(25.0 \%)$ eyes would have had ERSS $=1,4 / 20$ $(20.0 \%)$ eyes would have had ERSS $=2,2 / 20(10.0 \%)$ eyes would have ERSS $=3$, and $1 / 20(5.0 \%)$ eyes would have ERSS $=4$. Thus, 3/20 (15.0\%) eyes would have been considered to have moderate-to-high risk of ectasia following LASIK. 


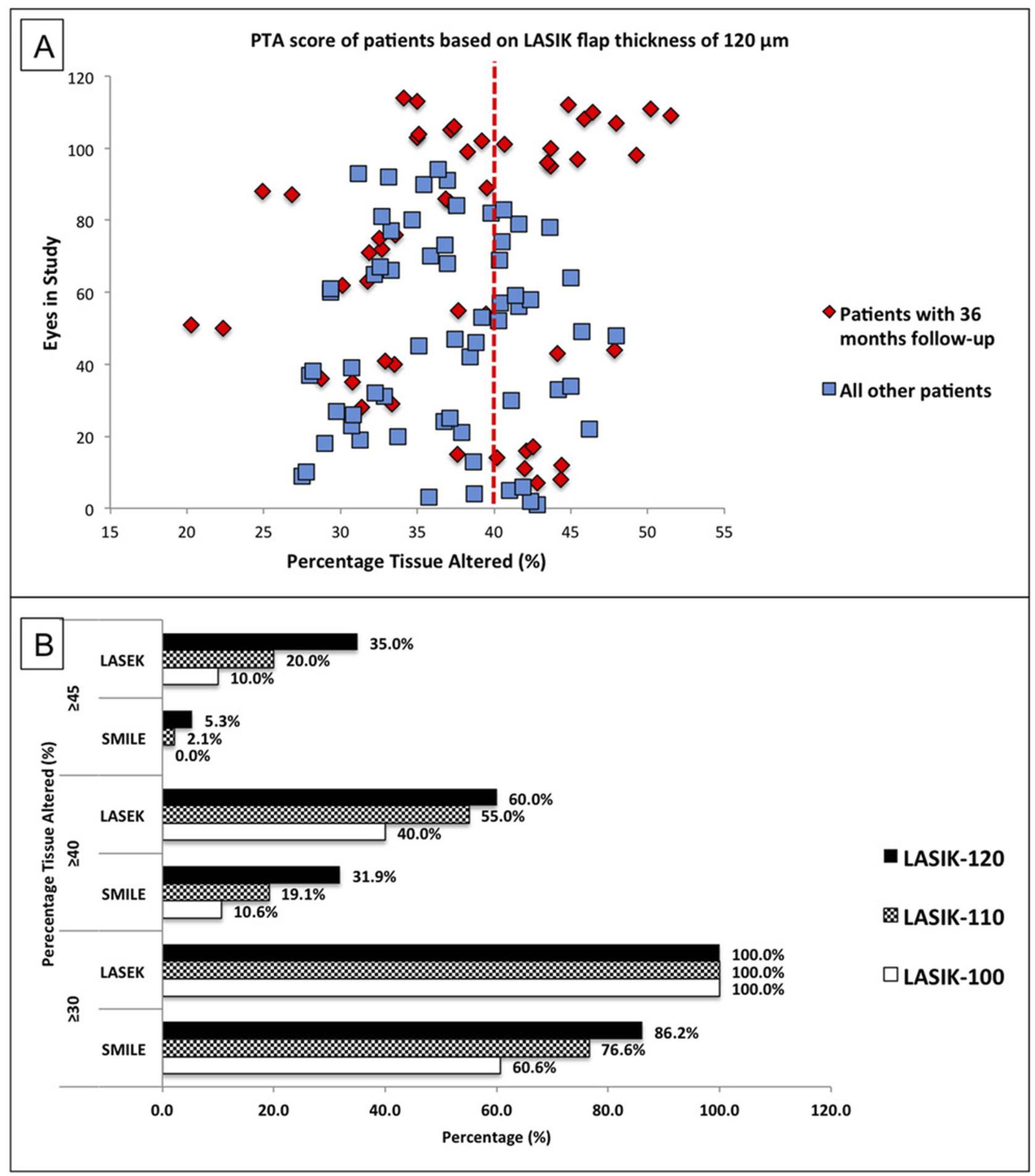

Figure I Percentage tissue altered (PTA) of eyes in study had laser in-situ keratomileusis (LASIK) been performed; these eyes subsequently underwent small incision lenticule extraction (SMILE) or laser-assisted sub-epithelial keratectomy (LASEK) procedures. (A) Scatter plot of PTA based on a LASIK flap thickness of I20 $\mu$ m highlighting patients with 36 months follow-up showing a significant proportion of eyes having PTA $\geq 40 \%$; (B) bar chart showing the proportion of patients in the study with PTA above fixed thresholds of $30 \%, 40 \%$, and $45 \%$ assuming different LASIK flap thicknesses.

Stability

Post-operative refraction remained stable within the 3-year follow-up period. Between the 3-month and 3-year follow-up time points, the difference in the mean spherical equivalent of manifest refraction was: $-0.30 \pm 0.48 \mathrm{D} ; 25.0 \%$ of eyes had a change in SE of $>0.50 \mathrm{D}$. 


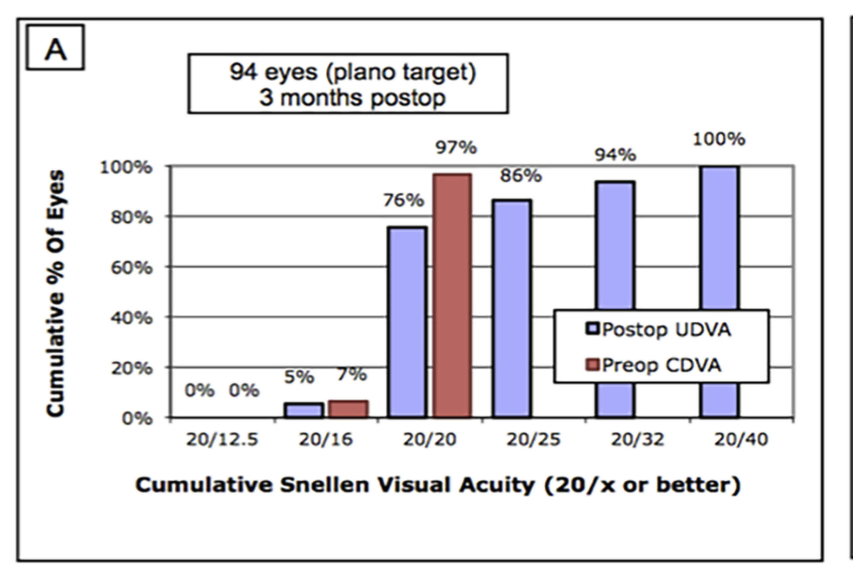

Uncorrected Distance Visual Acuity

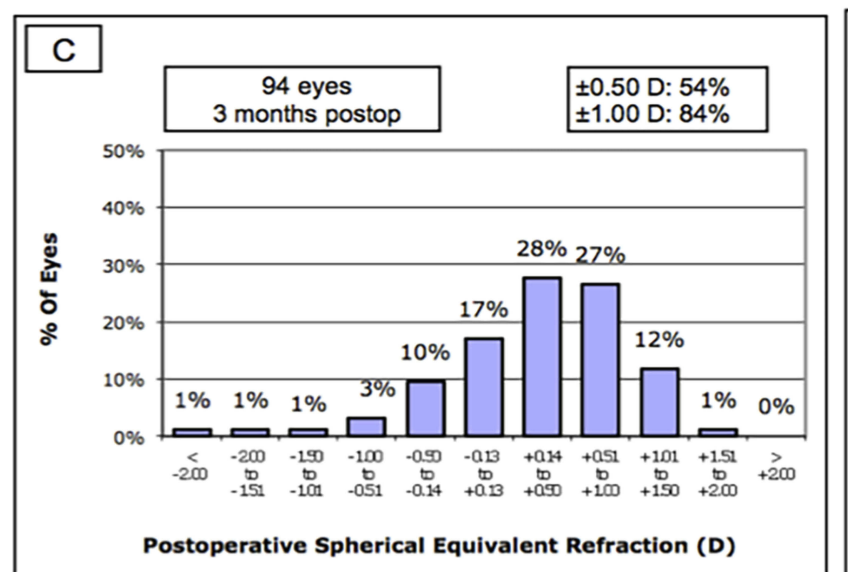

Spherical Equivalent Refractive Accuracy

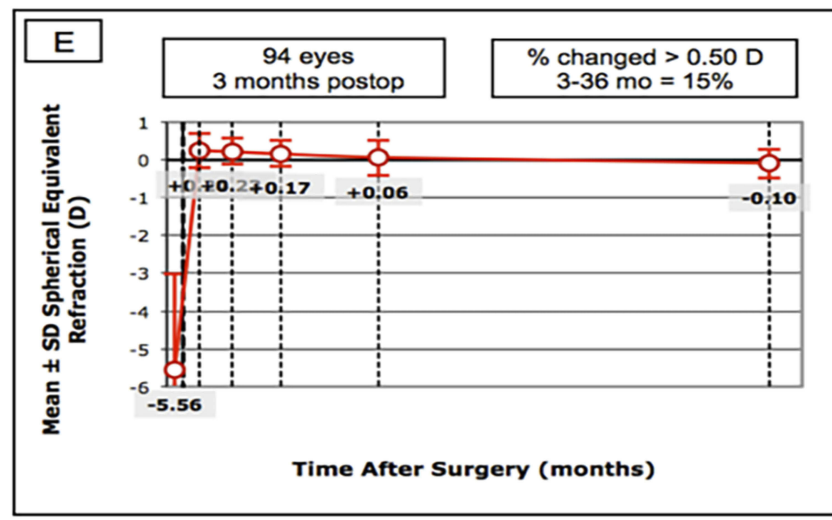

Stability of Spherical Equivalent Refraction

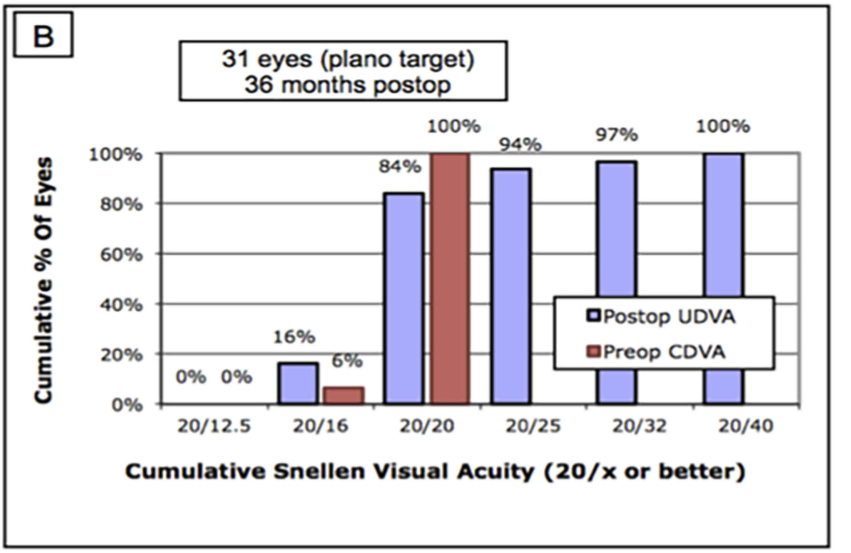

Uncorrected Distance Visual Acuity

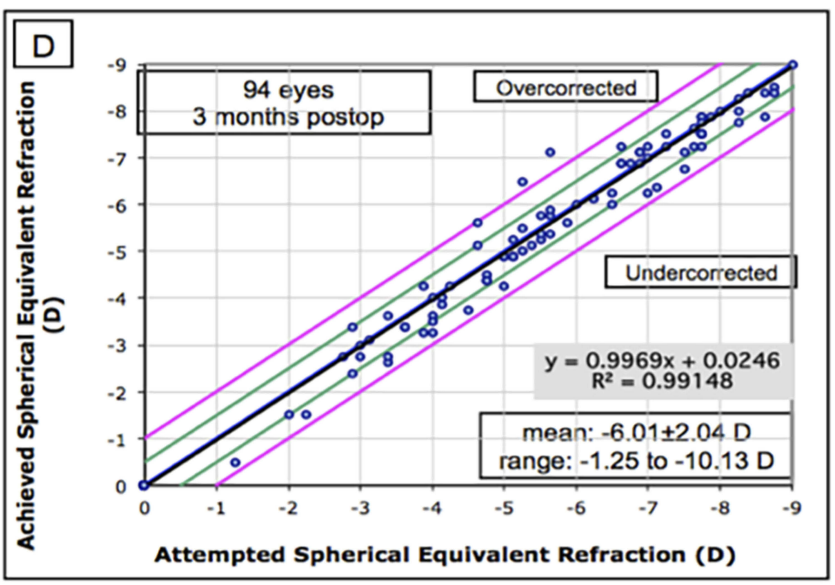

Spherical Equivalent Attempted vs Achieved

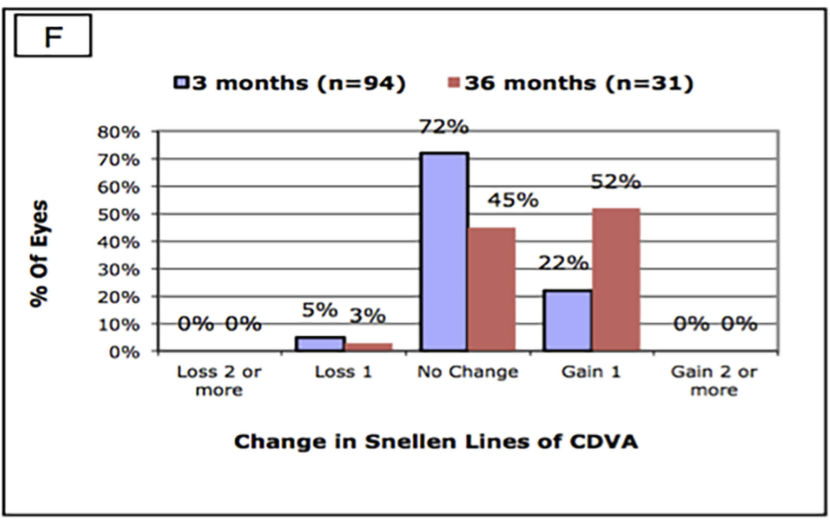

Change in Corrected Distance Visual Acuity

Figure 2 Refractive outcomes of eyes that underwent SMILE procedures. (A) Cumulative percentage of eyes in which the target refraction was zero that attained the specified levels of uncorrected distance visual acuity (UDVA) 3 months after surgery. CDVA = corrected distance visual acuity; (B) cumulative percentage of eyes in which the target refraction was zero that attained the specified levels of UDVA 3 years after surgery; (C) percentage of eyes with post-operative spherical equivalent refractions within intended target spherical equivalent refraction; (D) scatter plot and linear regression analysis of the attempted spherical equivalent refractive change versus the achieved spherical equivalent refractive change at 3 months after surgery; (E) stability of post-operative spherical equivalent at 3 years after surgery; (F) percentage of eyes in which there was a gain or loss of lines in CDVA 3 months and 3 years after surgery.

\section{Safety And Adverse Events}

None of the 20 eyes that underwent LASEK had postsurgical corneal ectasia at 3-year follow-up.

\section{Discussion}

In current clinical practice, several surgical options are available to myopic patients seeking refractive surgery. 
Laser-based refractive surgeries including LASIK, ASA procedures, and SMILE are currently the most popular. ${ }^{45}$ It is important for both clinicians and patients to understand the risks associated with the different procedures offered. Although most patients who have developed corneal ectasia following corneal refractive surgery have been shown to have identifiable risk factors pre-operatively, ${ }^{9-11}$ patients with normal pre-operative assessments are not necessarily insusceptible. ${ }^{46-50}$ This latter group poses specific challenges to the refractive surgeon.

Various nomograms and imaging-based technologies have been introduced to screen for and identify patients at risk of developing post-operative ectasia after LASIK. An example of a commonly used screening nomogram is the Ectasia Risk Score System (ERSS). ${ }^{11}$ This is based on known risk factors for the development of post-LASIK corneal ectasia, including: young age, high myopia, thin corneas, suspicious topographic patterns, and low residual stromal bed (RSB) thickness. ${ }^{9-11}$ Randleman et al validated this weighted risk stratification scale in 2008 and concluded that it has high sensitivity and specificity in predicting ectasia following LASIK. ${ }^{11}$

Imaging-based screening tools are predominantly based on indices derived from topographic parameters. Examples include the videokeratography-derived keratoconus prediction index (KPI) and the associated keratoconus index $(\mathrm{KCI}) \%$ described by Maeda et al. $^{51-53}$ Likewise, Rabinowitz et al introduced the central keratometric (K) index, the inferior-superior (I-S) index, and the keratometry, inferior-superior value, simulated astigmatism (KISA) $\%$ index, as screening indicators for ectasia. ${ }^{54,55}$ Other more recent imaging-based tools are based on corneal elevation profiles, ${ }^{39,56-59}$ corneal thickness profiles, ${ }^{39,57-59}$ difference corneal reference surfaces, ${ }^{60}$ abberometry, ${ }^{61}$ or combinations of these parameters (such as the cone location and magnitude index algorithm). ${ }^{62}$ These parameters are reported to have better sensitivities for detecting subclinical keratoconus. Software using some of these parameters, such as the SCORE Analyzer ${ }^{59}$ and $\mathrm{BAD},{ }^{39}$ have been incorporated within corneal tomography systems to screen for patients at risk of developing postoperative ectasia.

More recently, devices that screen for ectasia risk through assessing the in vivo biomechanics of patient corneas have gained popularity. ${ }^{63}$ Such devices include the ocular response analyzer (ORA; Reichert Ophthalmic Instruments) and the Corvis ST (Oculus). Some parameters derived from the ORA waveform, such as keratoconus match index (KMI) and the keratoconus match probability (KMP), have been shown to have good predictive accuracy for corneal ectasia risk, ${ }^{64}$ although other parameters derived using ORA applanation pressures, such as corneal hysteresis and corneal resistance factors, have not. ${ }^{65}$ The Corvis ST visualizes and monitors corneal deformation using an ultra-high-speed Scheimpflug camera. The Corvis biomechanical index (CBI), calculated using the deformation corneal response and the horizontal corneal thickness profile, has been shown to have high sensitivity and specificity in detecting corneal ectasia. ${ }^{66}$ The tomographic/biomechanical index (TBI) is another parameter that has been shown to have high accuracy in screening for subclinical corneal ectasia in patients with normal corneal topographies. ${ }^{67}$ It is derived by combining biomechanical data from the Corvis ST with data obtained from Pentacam HR Scheimpflug-based corneal tomography (Oculus).

PTA has been found to be a reliable measure for assessing the risk of post-operative ectasia, following LASIK, for eyes with normal pre-operative corneal topographies. ${ }^{18}$ Santhiago et al have shown that PTA had higher odds ratio and higher predictive capabilities for ectasia risk than moderate-to-high ERSS values, or individual factors from the ERSS system (CCT, RSB thickness, spherical equivalent refraction, ablation depth, and age of patients). ${ }^{18}$ With a sensitivity of $97 \%$ and specificity of $89 \%$, a PTA score $\geq 40 \%$ was recommended as a robust screening indicator for risk of corneal ectasia for patients with normal preoperative corneal topography, planning to undergo LASIK. Furthermore, Santhiago et al calculated the PTA for several case reports of ectasia following LASIK, with normal pre-operative corneal topographies, and found that PTA scores were $>40 \%$ for all these cases. ${ }^{18,46-50}$

Nonetheless, PTA does have its limitations. Accurate estimation of PTA depends on the actual thickness of the LASIK flaps created. ${ }^{68-70}$ It has been reported that the standard deviation of the thickness of flaps cut by mechanical microkeratomes can range from $12.4 \mu \mathrm{m}$ to $24.0 \mu \mathrm{m} .{ }^{68-70}$ For LASIK flaps cut by femtosecond lasers, standard deviations can range from $5.6 \mu \mathrm{m}$ to $16.0 \mu \mathrm{m} .{ }^{68-70}$ Consequently, even when thin LASIK flaps are planned, thicker flaps may be created, resulting in increased risk of post-LASIK corneal ectasia. Such variation in flap thickness may explain situations where patients develop unexpected post-LASIK corneal ectasia. ${ }^{71}$

In this study, using PTA and ERSS, we determined the risk of post-operative ectasia for eyes that presented for corneal refractive surgeries other than LASIK with normal 
corneal topographies and found that a significant number of eyes would have been considered to be "at risk" had LASIK been performed. Depending on presumed LASIK flap thickness, $10.6 \%$ to $31.9 \%$ of eyes that subsequently underwent SMILE, and $40.0 \%$ to $60.0 \%$ of eyes that subsequently underwent LASEK, had PTA $\geq 40 \%$. Again, depending on presumed LASIK flap thickness, the maximum calculated PTA scores ranged from $44.2 \%$ to $47.9 \%$ in the SMILE group and $46.9 \%$ to $51.5 \%$ in the LASEK group (Table 1). Data from previous studies suggest a PTA $>40 \%$ has a specificity of $89 \%$ in screening for corneal ectasia. ${ }^{18}$ By taking this into account, had these eyes undergone LASIK, we would have expected to observe corneal ectasia in at least 8 eyes in the SMILE group and 7 eyes in the LASEK group. When the ERSS was applied, $12.8 \%$ to $16.0 \%$ of SMILE eyes and $15.0 \%$ to $80.0 \%$ of LASEK eyes would have been considered to have moderate-to-high risk of post-LASIK ectasia. None of the eyes in this cohort were found to have post-operative corneal ectasia after a follow-up period of 3 years.

We can thus infer from our results that, compared to LASIK, the range of PTA, within which corneal refractive surgery can be performed safely on eyes with normal corneal topography, is likely to be wider when either SMILE or LASEK is performed. Opting for these procedures over LASIK may have minimized the risk of ectasia for these patients. None of our patients had pre-operative abnormal corneal topography. A recent study looking at PTA scores for patients with post-operative corneal ectasia after SMILE suggests that the threshold PTA value, below which surgery is safe, is significantly lower in patients with pre-operative topographic abnormality. ${ }^{38}$ Another similar study looking at patients with post-operative ectasia after photorefractive keratectomy also arrived at similar conclusions. ${ }^{72}$ Additionally, from our data, compared to SMILE eyes, a higher proportion of LASEK eyes would have had PTA scores above set thresholds (Table 1, Figure 1B); still, none of these eyes developed corneal ectasia. It is therefore probable that the "safe" PTA range is wider for LASEK than for SMILE.

As PTA represents the percentage of anterior corneal tissue that is modified during refractive surgery, for both SMILE and LASEK procedures, we can deduce that the alteration of a higher amount of corneal tissue is tolerated, before corneal ectasia develops. Furthermore, we can infer from these results that eyes with similar pre-operative parameters may be more likely to develop post-operative corneal ectasia with LASIK than with either SMILE or
LASEK. This study, therefore, provides some clinical evidence to support the hypothesis that SMILE procedure is associated with better biomechanical corneal stability than LASIK.

Compared to LASIK, the anterior lamellar fibres are relatively preserved in SMILE. Through human ex-vivo studies, it has been shown that vertical cuts through corneal lamellae, which occurs during LASIK flap creation, contribute to the loss of corneal structural integrity. ${ }^{73}$ This correlates with the depth of incisions. However, such changes in corneal biomechanics are not seen when horizontal delamination incisions are made. Often, fewer vertical incisions are made in current SMILE techniques compared to LASIK flap creation. This may explain why higher PTA scores may still be considered safer when SMILE is used in place of LASIK. As corneal structural integrity appears to be weakened when any side cuts are made, ${ }^{73}$ the absence of these incisions in LASEK may explain why it may be possible that LASEK may have a wider safe range of PTA than SMILE.

One potential limitation of this study is that we did not calculate PTA for these eyes using parameters that would have been more relevant for SMILE (e.g. lenticule thickness). As our aim was to compare the range of PTA values within which SMILE/LASEK was safe to established LASIK values. We standardized the method of PTA calculation to one where we supposed all patients would undergo LASIK. Taking into account the differences between LASIK and SMILE procedures, Santhiago et al and Moshirfar et al have recently proposed possible alternative calculations for PTA in SMILE. ${ }^{20,38}$ However, the use of these alternative calculations for PTA for eyes undergoing SMILE and their correlation with ectasia risk requires further evaluation. ${ }^{20,38}$ Indeed, the inaccuracies of the PTA metric, used in eyes undergoing refractive procedures other than LASIK, may explain the reason for the absence of ectasia even with high risk scores in our cohort.

Another limitation of this study is that, as no cases in our cohort developed postoperative ectasia, we are not able to determine a safe upper limit of PTA score for either SMILE or LASEK. Furthermore, the follow-up duration for this study was limited to 3 years. We acknowledge that corneal ectasia can occur at any time following corneal refractive surgery. However, it often presents within the first 12 post-operative months. ${ }^{9,10}$ Previous studies investigating post-LASIK ectasia have also used similar follow-up durations for identifying its incidence. ${ }^{11}$ Lastly, this study was conducted in a cohort of myopic 
patients in Singapore, a predominantly Asian population, with a high incidence of myopia. As differences in corneal biomechanical properties have been found in different ethnic groups, ${ }^{74}$ results from this study may not be applicable to all study populations.

In conclusion, both SMILE and LASEK are likely to alter the range of PTA within which corneal refractive surgery may be performed with lowered risks of postoperative ectasia. Eyes with PTA above the threshold of $>40 \%$ and considered to be at high risk of post-LASIK ectasia could potentially have either SMILE or LASEK. There may be patients with normal topography who, when found to have PTA $>40 \%$, elect to have non-corneal procedures such as implantable contact lenses. For these patients, we may be able to offer either SMILE or LASEK as safe, less-invasive alternatives. However, it was beyond the remit of this study to provide recommended guidance of PTA scores that SMILE or LASEK can be performed safely. To better ascertain this, further evaluation of the use of PTA as a tool in assessing ectasia risk following SMILE or LASEK is required; and, a safe upper limit of PTA for these procedures needs to be established.

\section{Ethics}

SingHealth Centralised Institutional Review Board.

\section{Acknowledgment}

Geraint P. Williams' SERI fellowship is supported by a Dowager Eleanor Peel Trust Travelling Grant and a Royal College of Ophthalmologists/Pfizer Ophthalmic Fellowship.

\section{Disclosure}

Dr Marcony R Santhiago is a consultant at Ziemer, Alcon, and Zeiss. The authors report no other conflicts of interest in this work.

\section{References}

1. Sugar A, Rapuano CJ, Culbertson WW, et al. Laser in situ keratomileusis for myopia and astigmatism: safety and efficacy: a report by the American Academy of Ophthalmology. Ophthalmology. 2002;109:175-187. doi:10.1016/s0161-6420(01)00966-6

2. Dupps WJ Jr., Wilson SE. Biomechanics and wound healing in the cornea. Exp Eye Res. 2006;83:709-720. doi:10.1016/j.exer.2006.03. 015

3. Santhiago MR, Wilson SE. Cellular effects after laser in situ keratomileusis flap formation with femtosecond lasers: a review. Cornea. 2012;31:198-205. doi:10.1097/ICO.0b013e3182068c42

4. Smolek MK, McCarey BE. Interlamellar adhesive strength in human eyebank corneas. Invest Ophthalmol Vis Sci. 1990;31:1087-1095.
5. Muller LJ, Pels E, Vrensen GF. The specific architecture of the anterior stroma accounts for maintenance of corneal curvature. $\mathrm{Br} J$ Ophthalmol. 2001;85:437-443. doi:10.1136/bjo.85.4.437

6. Dawson DG, Grossniklaus HE, McCarey BE, Edelhauser HF. Biomechanical and wound healing characteristics of corneas after excimer laser keratorefractive surgery: is there a difference between advanced surface ablation and sub-Bowman's keratomileusis? $J$ Refract Surg. 2008;24:S90-6. doi:10.3928/1081597X-20080101-16

7. Randleman JB, Dawson DG, Grossniklaus HE, McCarey BE, Edelhauser HF. Depth-dependent cohesive tensile strength in human donor corneas: implications for refractive surgery. J Refract Surg. 2008;24:S85-9. doi:10.3928/1081597X-20080101-15

8. Roberts CJ, Dupps WJ Jr. Biomechanics of corneal ectasia and biomechanical treatments. J Cataract Refract Surg. 2014;40:991998. doi:10.1016/j.jcrs.2014.04.013

9. Randleman JB, Russell B, Ward MA, Thompson KP, Stulting RD. Risk factors and prognosis for corneal ectasia after LASIK. Ophthalmology. 2003;110:267-275. doi:10.1016/S0161-6420(02)01 727-X

10. Randleman JB, Trattler WB, Stulting RD. Validation of the ectasia risk score system for preoperative laser in situ keratomileusis screening. Am J Ophthalmol. 2008;145:813-818. doi:10.1016/j.ajo.2007.12.033

11. Randleman JB, Woodward M, Lynn MJ, Stulting RD. Risk assessment for ectasia after corneal refractive surgery. Ophthalmology. 2008;115:37-50. doi:10.1016/j.ophtha.2007.03.073

12. Pallikaris IG, Kymionis GD, Astyrakakis NI. Corneal ectasia induced by laser in situ keratomileusis. $J$ Cataract Refract Surg. 2001;27:1796-1802. doi:10.1016/s0886-3350(01)01090-2

13. Rad AS, Jabbarvand M, Saifi N. Progressive keratectasia after laser in situ keratomileusis. J Refract Surg. 2004;20:S718-22.

14. Bohac M, Koncarevic M, Pasalic A, et al. Incidence and clinical characteristics of post LASIK ectasia: a review of over 30,000 LASIK cases. Semin Ophthalmol. 2018;33:869-877. doi:10.1080/ 08820538.2018.1539183

15. Amoils SP, Deist MB, Gous P, Amoils PM. Iatrogenic keratectasia after laser in situ keratomileusis for less than -4.0 to -7.0 diopters of myopia. J Cataract Refract Surg. 2000;26:967-977. doi:10.1016/s0 886-3350(00)00434-x

16. Seo KY, Lee JH, Kim MJ, et al. Effect of suturing on latrogenic keratectasia after laser in situ keratomileusis. J Refract Surg. 2004;20:40-45.

17. Parmar D, Claoue C. Keratectasia following excimer laser photorefractive keratectomy. Acta Ophthalmol Scand. 2004;82:102-105.

18. Santhiago MR, Smadja D, Gomes BF, et al. Association between the percent tissue altered and post-laser in situ keratomileusis ectasia in eyes with normal preoperative topography. Am J Ophthalmol. 2014;158:87-95 e1. doi:10.1016/j.ajo.2014.04.002

19. Santhiago MR, Smadja D, Wilson SE, Krueger RR, Monteiro ML, Randleman JB. Role of percent tissue altered on ectasia after LASIK in eyes with suspicious topography. $J$ Refract Surg. 2015;31:258265. doi:10.3928/1081597X-20150319-05

20. Santhiago MR. Percent tissue altered and corneal ectasia. Curr Opin Ophthalmol. 2016;27:311-315. doi:10.1097/ICU.0000000000000276

21. Santhiago MR, Wilson SE, Smadja D, Chamon W, Krueger RE, Randleman JB. Validation of the Percent Tissue Altered as a Risk Factor for Ectasia after LASIK. Ophthalmology. 2019;126:908-909. doi:10.1016/j.ophtha.2019.01.018

22. Garcia-Gonzalez M, Drake Rodriguez-Casanova P, Rodriguez-Perez I, Rodero A, Teus MA. Long-term follow-up of LASEK with mitomycin C performed to correct myopia in thin corneas. J Refract Surg. 2017;33:813-819. doi:10.3928/1081597X-20171004-06

23. Sekundo W, Kunert KS, Blum M. Small incision corneal refractive surgery using the small incision lenticule extraction (SMILE) procedure for the correction of myopia and myopic astigmatism: results of a 6 month prospective study. Br J Ophthalmol. 2011;95:335-339. doi:10.1136/bjo.2009.174284 
24. Shah R, Shah S, Sengupta S. Results of small incision lenticule extraction: all-in-one femtosecond laser refractive surgery. J Cataract Refract Surg. 2011;37:127-137. doi:10.1016/j.jcrs.2010.07.033

25. Reinstein DZ, Archer TJ, Randleman JB. Mathematical model to compare the relative tensile strength of the cornea after PRK, LASIK, and small incision lenticule extraction. J Refract Surg. 2013;29:454-460. doi:10.3928/1081597X-20130617-03

26. Sinha Roy A, Dupps WJ Jr., Roberts CJ. Comparison of biomechanical effects of small-incision lenticule extraction and laser in situ keratomileusis: finite-element analysis. J Cataract Refract Surg. 2014;40:971-980. doi:10.1016/j.jcrs.2013.08.065

27. Wang D, Liu M, Chen Y, et al. Differences in the corneal biomechanical changes after SMILE and LASIK. J Refract Surg. 2014;30:702707. doi:10.3928/1081597X-20140903-09

28. Wu D, Wang Y, Zhang L, Wei S, Tang X. Corneal biomechanical effects: small-incision lenticule extraction versus femtosecond laserassisted laser in situ keratomileusis. J Cataract Refract Surg. 2014;40:954-962. doi:10.1016/j.jcrs.2013.07.056

29. Osman IM, Helaly HA, Abdalla M, Shousha MA. Corneal biomechanical changes in eyes with small incision lenticule extraction and laser assisted in situ keratomileusis. BMC Ophthalmol. 2016;16:123. doi:10.1186/s12886-016-0304-3

30. Pedersen IB, Bak-Nielsen S, Vestergaard AH, Ivarsen A, Hjortdal J. Corneal biomechanical properties after LASIK, ReLEx flex, and ReLEx smile by scheimpflug-based dynamic tonometry. Graefes Arch Clin Exp Ophthalmol. 2014;252:1329-1335. doi:10.1007/s00417-014-2667-6

31. Sefat SM, Wiltfang R, Bechmann M, Mayer WJ, Kampik A, Kook D. Evaluation of changes in human corneas after femtosecond LaserAssisted LASIK and Small-Incision Lenticule Extraction (SMILE) using non-contact tonometry and ultra-high-speed camera (Corvis ST). Curr Eye Res. 2016;41:917-922. doi:10.3109/02713683.2015.1082185

32. Shen Y, Chen Z, Knorz MC, Li M, Zhao J, Zhou X. Comparison of corneal deformation parameters after SMILE, LASEK, and femtosecond laser-assisted LASIK. J Refract Surg. 2014;30:310-318.

33. Sachdev G, Sachdev MS, Sachdev R, Gupta H. Unilateral corneal ectasia following small-incision lenticule extraction. J Cataract Refract Surg. 2015;41:2014-2018. doi:10.1016/j.jcrs.2015.08.006

34. Mastropasqua L. Bilateral ectasia after femtosecond laser-assisted small-incision lenticule extraction. $J$ Cataract Refract Surg. 2015;41:1338-1339. doi:10.1016/j.jcrs.2015.05.013

35. Wang Y, Cui C, Li Z, et al. Corneal ectasia 6.5 months after smallincision lenticule extraction. J Cataract Refract Surg. 2015;41:11001106. doi:10.1016/j.jcrs.2015.04.001

36. El-Naggar MT. Bilateral ectasia after femtosecond laser-assisted small-incision lenticule extraction. $J$ Cataract Refract Surg. 2015;41:884-888. doi:10.1016/j.jcrs.2015.02.008

37. Mattila JS, Holopainen JM. Bilateral ectasia after femtosecond laserassisted Small Incision Lenticule Extraction (SMILE). J Refract Surg. 2016;32:497-500. doi:10.3928/1081597X-20160502-03

38. Moshirfar M, Albarracin JC, Desautels JD, Birdsong OC, Linn SH, Hoopes PC Sr. Ectasia following small-incision lenticule extraction (SMILE): a review of the literature. Clin Ophthalmol. 2017;11:16831688. doi:10.2147/OPTH.S147011

39. Muftuoglu O, Ayar O, Ozulken K, Ozyol E, Akinci A. Posterior corneal elevation and back difference corneal elevation in diagnosing forme fruste keratoconus in the fellow eyes of unilateral keratoconus patients. J Cataract Refract Surg. 2013;39:1348-1357. doi:10.1016/j. jcrs.2013.03.023

40. Ang M, Tan D, Mehta JS. Small incision lenticule extraction (SMILE) versus laser in-situ keratomileusis (LASIK): study protocol for a randomized, non-inferiority trial. Trials. 2012;13:75. doi:10. 1186/1745-6215-13-75

41. Ang M, Mehta JS, Chan C, Htoon HM, Koh JC, Tan DT. Refractive lenticule extraction: transition and comparison of 3 surgical techniques. J Cataract Refract Surg. 2014;40:1415-1424. doi:10.1016/j. jcrs.2013.12.026
42. Armstrong RA. Statistical guidelines for the analysis of data obtained from one or both eyes. Ophthalmic Physiol Opt. 2013;33:7-14. doi:10.1111/opo.2012.33.issue-1

43. Tan DK, Tay WT, Chan C, Tan DT, Mehta JS. Postoperative ocular higher-order aberrations and contrast sensitivity: femtosecond lenticule extraction versus pseudo small-incision lenticule extraction. $J$ Cataract Refract Surg. 2015;41:623-634. doi:10.1016/j.jcrs.2014.07. 032

44. Wong JX, Wong EP, Htoon HM, Mehta JS. Intraoperative centration during small incision lenticule extraction (SMILE). Medicine. 2017;96:e6076. doi:10.1097/MD.0000000000006076

45. Pillar A, Krueger R. Advances in refractive surgery: june 2014 to july 2015. Asia Pac J Clin Oncol. 2016;5:212-222. doi:10.1097/APO. 0000000000000200

46. Klein SR, Epstein RJ, Randleman JB, Stulting RD. Corneal ectasia after laser in situ keratomileusis in patients without apparent preoperative risk factors. Cornea. 2006;25:388-403. doi:10.1097/01.ico. 0000222479.68242 .77

47. Saad A, Gatinel D. Bilateral corneal ectasia after laser in situ keratomileusis in patient with isolated difference in central corneal thickness between eyes. J Cataract Refract Surg. 2010;36:1033-1035. doi:10.1016/j.jcrs.2010.03.023

48. Ambrosio R Jr., Dawson DG, Salomao M, Guerra FP, Caiado AL, Belin MW. Corneal ectasia after LASIK despite low preoperative risk: tomographic and biomechanical findings in the unoperated, stable, fellow eye. J Refract Surg. 2010;26:906-911. doi:10.3928/ 1081597X-20100428-02

49. Goncalves FA, Goncalves JM. Corneal ectasia after LASIK in a patient with normal scheimpflug evaluation but a high ectasia risk score. $J$ Refract Surg. 2013;29:792-795. doi:10.3928/1081597X-20130813-01

50. Alio JL, Muftuoglu O, Ortiz D, et al. Ten-year follow-up of laser in situ keratomileusis for high myopia. Am J Ophthalmol. 2008;145:5564. doi:10.1016/j.ajo.2007.08.035

51. Maeda N, Klyce SD, Smolek MK, Thompson HW. Automated keratoconus screening with corneal topography analysis. Invest Ophthalmol Vis Sci. 1994;35:2749-2757.

52. Maeda N, Klyce SD, Tano Y. Detection and classification of mild irregular astigmatism in patients with good visual acuity. Surv Ophthalmol. 1998;43:53-58.

53. Maeda N, Klyce SD, Smolek MK. Comparison of methods for detecting keratoconus using videokeratography. Arch Ophthalmol. 1995;113:870-874. doi:10.1001/archopht.1995.01100070044023

54. Rabinowitz YS. Videokeratographic indices to aid in screening for keratoconus. J Refract Surg. 1995;11:371-379.

55. Rabinowitz YS, Rasheed K. KISA\% index: a quantitative videokeratography algorithm embodying minimal topographic criteria for diagnosing keratoconus. J Cataract Refract Surg. 1999;25:13271335. doi:10.1016/s0886-3350(99)00195-9

56. Smadja D, Touboul D, Cohen A, et al. Detection of subclinical keratoconus using an automated decision tree classification. Am J Ophthalmol. 2013;156:237-46 e1. doi:10.1016/j.ajo.2013.03.034

57. Ambrosio R Jr., Alonso RS, Luz A, Coca Velarde LG. Cornealthickness spatial profile and corneal-volume distribution: tomographic indices to detect keratoconus. J Cataract Refract Surg. 2006;32:1851-1859. doi:10.1016/j.jcrs.2006.06.025

58. Ambrosio R Jr., Caiado AL, Guerra FP, et al. Novel pachymetric parameters based on corneal tomography for diagnosing keratoconus. $J$ Refract Surg. 2011;27:753-758. doi:10.3928/1081597X-20110721-01

59. Chan C, Ang M, Saad A, et al. Validation of an objective scoring system for forme fruste keratoconus detection and post-LASIK ectasia risk assessment in Asian eyes. Cornea. 2015;34:996-1004. doi:10.1097/ICO.0000000000000529

60. Smadja D, Santhiago MR, Mello GR, Krueger RR, Colin J, Touboul D. Influence of the reference surface shape for discriminating between normal corneas, subclinical keratoconus, and keratoconus. J Refract Surg. 2013;29:274-281. doi:10.3928/1081597X-20130318-07 
61. Buhren J, Kook D, Yoon G, Kohnen T. Detection of subclinical keratoconus by using corneal anterior and posterior surface aberrations and thickness spatial profiles. Invest Ophthalmol Vis Sci. 2010;51:3424-3432. doi:10.1167/iovs.09-4960

62. Mahmoud AM, Nunez MX, Blanco C, et al. Expanding the cone location and magnitude index to include corneal thickness and posterior surface information for the detection of keratoconus. Am J Ophthalmol. 2013;156:1102-1111. doi:10.1016/j.ajo.2013.07.018

63. Gomes JA, Tan D, Rapuano CJ, et al. Global consensus on keratoconus and ectatic diseases. Cornea. 2015;34:359-369. doi:10.1097/ ICO.0000000000000408

64. Labiris G, Giarmoukakis A, Gatzioufas Z, Sideroudi H, Kozobolis V, Seitz B. Diagnostic capacity of the keratoconus match index and keratoconus match probability in subclinical keratoconus. J Cataract Refract Surg. 2014;40:999-1005. doi:10.1016/j.jcrs.2013.08.064

65. Fontes BM, Ambrosio R Jr., Jardim D, Velarde GC, Nose W. Corneal biomechanical metrics and anterior segment parameters in mild keratoconus. Ophthalmology. 2010;117:673-679. doi:10.1016/j.ophtha.2009. 09.023

66. Vinciguerra R, Ambrosio R Jr., Elsheikh A, et al. Detection of keratoconus with a new biomechanical index. J Refract Surg. 2016;32:803-810. doi:10.3928/1081597X-20160629-01

67. Ambrosio R Jr., Lopes BT, Faria-Correia F, et al. Integration of scheimpflug-based corneal tomography and biomechanical assessments for enhancing ectasia detection. J Refract Surg. 2017;33:434 443. doi:10.3928/1081597X-20170426-02
68. Talamo JH, Meltzer J, Gardner J. Reproducibility of flap thickness with intraLase FS and Moria LSK-1 and M2 microkeratomes. $J$ Refract Surg. 2006;22:556-561.

69. Patel SV, Maguire LJ, McLaren JW, Hodge DO, Bourne WM. Femtosecond laser versus mechanical microkeratome for LASIK: a randomized controlled study. Ophthalmology. 2007;114:1482-1490. doi:10.1016/j.ophtha.2006.10.057

70. Kanellopoulos AJ, Asimellis G. Three-dimensional LASIK flap thickness variability: topographic central, paracentral and peripheral assessment, in flaps created by a mechanical microkeratome (M2) and two different femtosecond lasers (FS60 and FS200). Clin Ophthalmol. 2013;7:675-683. doi:10.2147/OPTH.S40762

71. Reinstein DZ, Srivannaboon S, Archer TJ, Silverman RH, Sutton H, Coleman DJ. Probability model of the inaccuracy of residual stromal thickness prediction to reduce the risk of ectasia after LASIK part I: quantifying individual risk. $J$ Refract Surg. 2006;22:851-860.

72. Sorkin N, Kaiserman I, Domniz Y, Sela T, Munzer G, Varssano D. Risk assessment for corneal ectasia following photorefractive keratectomy. $J$ Ophthalmol. 2017;2017:2434830. doi:10.1155/2017/2434830

73. Knox Cartwright NE, Tyrer JR, Jaycock PD, Marshall J. Effects of variation in depth and side cut angulations in LASIK and thin-flap LASIK using a femtosecond laser: a biomechanical study. $J$ Refract Surg. 2012;28:419-425. doi:10.3928/1081597X-20120518-07

74. Lazreg S, Mesplie N, Praud D, et al. Comparison of corneal thickness and biomechanical properties between North African and French patients. $J$ Cataract Refract Surg. 2013;39:425-430. doi:10.1016/j.jcrs.2012.09.015
Clinical Ophthalmology

\section{Publish your work in this journal}

Clinical Ophthalmology is an international, peer-reviewed journal covering all subspecialties within ophthalmology. Key topics include: Optometry; Visual science; Pharmacology and drug therapy in eye diseases; Basic Sciences; Primary and Secondary eye care; Patient Safety and Quality of Care Improvements. This journal is indexed on PubMed
Dovepress

Central and CAS, and is the official journal of The Society of Clinical Ophthalmology (SCO). The manuscript management system is completely online and includes a very quick and fair peer-review system, which is all easy to use. Visit http://www.dovepress.com/ testimonials.php to read real quotes from published authors. 